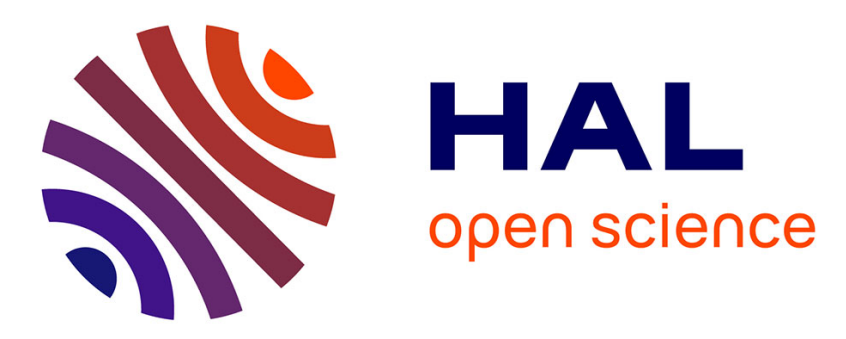

\title{
Off-line method to determine the electrode balancing of Li-ion batteries
}

Karrick Mergo Mbeya, Nicolas Damay, Guy Friedrich, Christophe Forgez, Maxime Juston

\section{To cite this version:}

Karrick Mergo Mbeya, Nicolas Damay, Guy Friedrich, Christophe Forgez, Maxime Juston. Off-line method to determine the electrode balancing of Li-ion batteries. Mathematics and Computers in Simulation, inPress. hal-02495608

\section{HAL Id: hal-02495608 \\ https://hal.science/hal-02495608}

Submitted on 2 Mar 2020

HAL is a multi-disciplinary open access archive for the deposit and dissemination of scientific research documents, whether they are published or not. The documents may come from teaching and research institutions in France or abroad, or from public or private research centers.
L'archive ouverte pluridisciplinaire HAL, est destinée au dépôt et à la diffusion de documents scientifiques de niveau recherche, publiés ou non, émanant des établissements d'enseignement et de recherche français ou étrangers, des laboratoires publics ou privés. 


\title{
Off-line method to determine the electrode balancing of Li-ion batteries
}

\author{
Karrick Mergo Mbeya, Nicolas Damay, Guy Friedrich, Christophe Forgez, Maxime Juston. \\ Sorbonne Université, Université de Technologie de Compiègne, CNRS, FRE 2012 Roberval, Centre de recherche Royallieu, CS 60319, 60203 \\ Compiègne Cedex, France.
}

\begin{abstract}
In this paper, we propose a non-invasive method to determine the electrode balancing of the lithium-ion batteries, which is the determination of (i) individual electrodes capacities and (ii) individual curves of equilibrium potentials of the electrodes as functions of the battery state of charge. The proposed method requires the average measurements of the battery voltage between discharge and charge for a low current. This averaged voltage is then associated with the reference average curves of the electrode equilibrium potentials issued from literature. To determine the electrode balancing, the method was first used on a pristine $\mathrm{LiFePO}_{4} /$ graphite cell. The results are consitent with this cell data and the proposed method accuracy is compared to a reference method of the litterature. We then used the proposed method on an aged cell of the same type to evaluate the method robustness with respect to the change in the cell state of health. The tracking of each electrode capacity during the battery lifespan can be used as a non-invasive diagnosis tool to monitor the state of health evolution to each electrode. Furthermore, the access to the individual curves of electrodes equilibrium potentials as functions of the battery state of charge is the first step towards the implementation of a non-invasive tool for an optimal prediction of the battery operating limits during fast recharging.
\end{abstract}

Keywords: Electrode balancing, electrode capacities, electrode equilibrium potential, lithiation rate, battery voltage, battery overvoltage, low current.

\section{Introduction}

The lithium-ion batteries (LIBs) are among the best energy storage systems offering high power and energy density (at element scale, the energy density can reach $260 W h . \mathrm{kg}^{-1}$ ), with a very low rate of self-discharge [1]. Thanks to these features, the LIBs are ubiquitous in various areas of use, from electronic devices to transport (electric vehicles, etc.).

The use of LIBs requires the monitoring of their state (temperature, state of charge, state of health, etc.) with a battery management system (BMS) to ensure safety, better performances and lifespan. Classically, the monitoring of LIBs is made by considering them as a "black box", i.e. without any information about their internal states [2]. However, a Li-ion cell is made up of different internal elements, including positive and negative electrodes with their respective active-materials, electrolyte, current collectors and separator (Figure 1).

The decrease in autonomy (capacity loss) and power fading (impedance rise) of a LIB during its lifespan are mainly consequences of unwanted reactions that occur at the electrodes [3]. We can cite, for instance, lithium

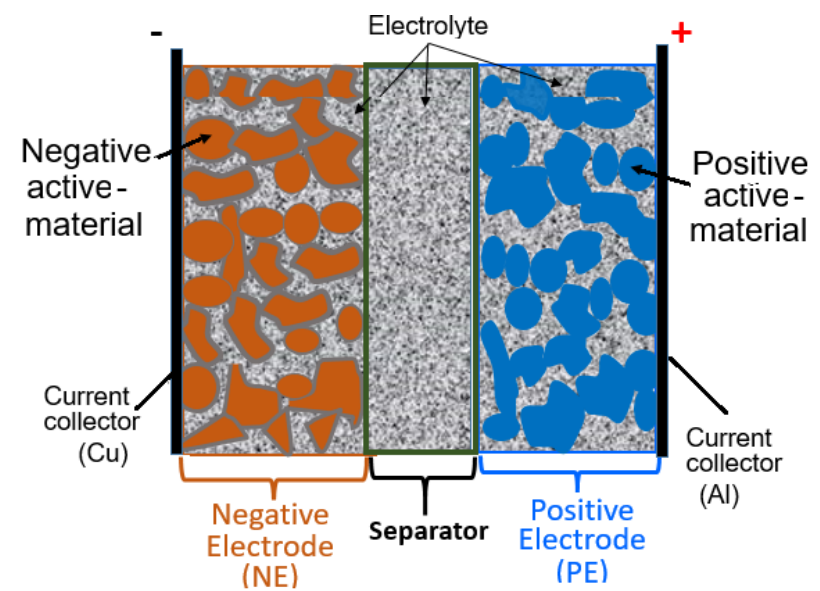

Figure 1: Main internal elements of a lithium-ion cell.

plating reaction, growth of SEI layer (Solid Electrolyte Interface) and cracking particles at the graphite negative electrode and structure change in active-material of positive electrode. Therefore, it seems appropriate to monitor the electrode states individually. This will lead to a meaningful diagnosis of the battery and an optimal prediction of its operating limits. 
An electrode state can be defined by many quantities. Here we focus on the determination of the capacity of each electrode and the curve of equilibrium potential, (also called $O C P$, Open Circuit Potential), as a function of the battery state of charge $(S o C)$ for each electrode. These quantities are related to the electrode active-material properties and allow to characterize the electrode states of health.

The electrode capacity and $O C P$ curve are equilibrium properties, (at zero current), of an electrode. In order to get these quantities, non-invasive approaches combine the active material properties of the electrodes, ( $O C P$ curves from half cells), with cell voltage measurements at low and steady current. Authors in $[4,6,8]$ used measured cell voltage in charge and other authors in $[5,7]$ used cell voltage measured in discharge. Even measured at a very low and constant current, the cell voltage always show a significant rise or drop, (overvoltage), with respect to equilibrium voltage, depending whether the cell is charged or discharged respectively (Figure 2.b) [9]. By using measured cell voltage either in charge or discharge, the overvoltage cannot be properly taken into account. As a consequence, the overvoltage contribution brings a bias on the estimation of the aformentiened electrode quantities. This bias could be acceptable for online application. In this study, we propose to use both the charge and discharge curves at a low and constant current. It is expected that the proposed method leads to a better compensation of the overvoltage, resulting in a more accurate determination of these electrode properties. Since discharging battery at a constant current is difficult to achieve in online application, the proposed method is for off-line application. It can be used in industrial or academic labs to study the ageing processes of the cells. For example, the method can be used in the diagnosis of the cells at the end of the first life for a second life use.

Note that other methods, categorized as invasive approach, are also used in the literature for determining the electrode $O C P$ curves or the electrode capacities. For instance, authors in $[10,11,12]$ used a reference electrode, (with the so-called 3-electrodes cell), to measure the electrode $O C P$ of batteries. Authors in [13, 15] analytically calculated the electrode capacities from the electrode design parameters, such as the porosity, the thickness and the active area. In [14], Bennett et al. used the mass of active-materials to calculate the electrode capacities.

The remainder of this document is structured as follows: in section 2, we describe the composition of LIB voltage curve for a low constant-current and we also establish the equations which relate the electrode state quantities with the battery voltage. In section 3, we describe the proposed method used to separate these quantities from the battery voltage. In section 4 , we discuss the results. And, in section 5 we discuss the robustness of the method.

\section{Characteristics of LIBs pseudo-OCV}

\subsection{Pseudo-OCV definition and modeling}

The pseudo-OCV ( $p O C V$ ) is defined as the battery voltage when its overvoltage $(\eta)$ is about a few tens of millivolts (i.e, at very low current) (Equation (1)) (Figure 2.a) [16].

$$
p O C V=O C V+\eta
$$

OCV (Open Circuit Voltage) represents the battery voltage at zero current. This quantity varies with the battery state of charge $(S o C)$, the temperature $(T)$ and the operation history (see the hysteresis between charge $O C V_{\text {cha }}$ and discharge $O C V_{d i s}$ in Figure 2.b).

The battery $O C V$ curve is full of information (see sub-

a)

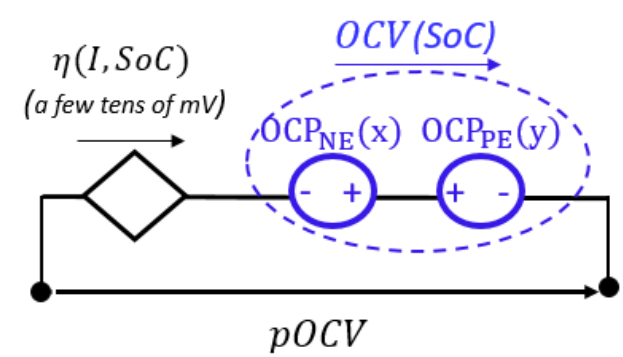

b)

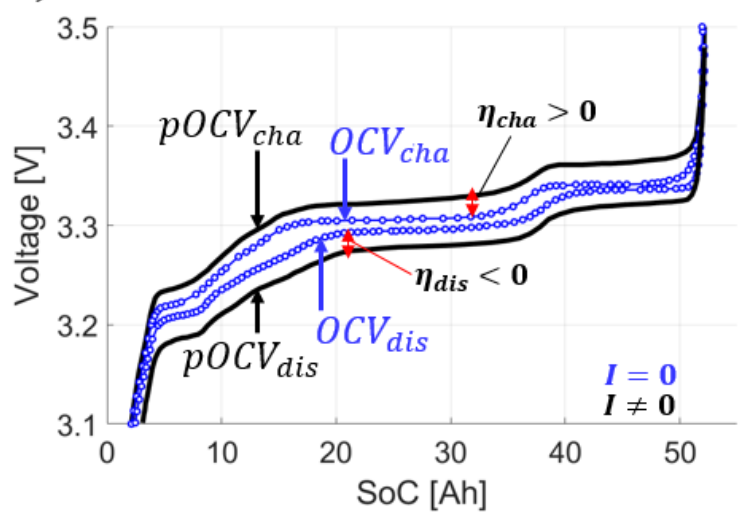

Figure 2: a) Battery electric circuit model. b) Discharge and charge curves of $p O C V(\mathrm{C} / 50)$ and $O C V$ of a $\mathrm{LiFePO}_{4} /$ graphite $\mathrm{LIB}$, (The data are issued from the ref. [20]). Color should be used for this figure in print.

section 2.2), but is difficult to get. The $O C V$ measurements at different $S o C$ requires long tests [17]. As a consequence, $p O C V$ measurements are often used to 
save time and to get information [18, 19]. However, from Figure 2.b, it can be seen that the battery overvoltage $\eta$ causes vertical and horizontal shifts in the $p O C V$ curve compared to the $O C V$ curve. The battery overvoltage $\eta$ is due to various phenomena inside the battery. These phenomena are ohmic effects (conduction of lithium ions and electrons, charge transfer process, etc.) and dynamic effects (diffusions processes) [21, 22]. As a consequence, the battery overvoltage can evolve with parameters such as temperature $(T)$, current $(I)$, state of charge $(S o C)$ and history of the battery (charge, discharge, and state of health of the battery). Here we are interested in the $p O C V$ dependency on the battery $S o C$. The latter can be calculated by Equation (2). The other parameters aforementioned are considered to be constant.

$$
S o C=S o C_{i n i}+\frac{1}{3600} \int_{t_{0}}^{t 0+\Delta t} I(t) d t
$$

$S o C_{i n i}$ is the initial state of charge [Ah], $I$ the applied current $[\mathrm{A}], t_{0}$ the initial time $[\mathrm{s}]$ and $\Delta t$ the duration of the charge/discharge.

\subsection{Equilibrium voltage}

\subsubsection{Description}

The battery $O C V$ represents the difference between the equilibrium potentials $(O C P)$ of positive and negative electrodes (Equation (3)).

$$
O C V(S o C)=O C P_{P E}(y)-O C P_{N E}(x)
$$

The subscripts $P E$ and $N E$ stand respectively for positive and negative electrodes. $x$ and $y$ are respectively the lithiation rates of the electrodes, which are defined as follows:

- For NE: $x=\frac{c_{s, N E}^{a v g}}{c_{s, N E}^{m a x}}$, where $c_{s, N E}^{a v g}\left[\mathrm{~mol} / \mathrm{cm}^{3}\right]$ and $c_{s, N E}^{\max }\left[\mathrm{mol} / \mathrm{cm}^{3}\right]$ are respectively the average and the maximal concentrations of lithium in the $\mathrm{NE}$ active-material.

- For PE: $y=\frac{c_{s, P E}^{a v g}}{c_{s, P E}^{m a x}}$, where $c_{s, P E}^{a v g}\left[\mathrm{~mol} / \mathrm{cm}^{3}\right]$ and $c_{s, P E}^{\max }\left[\mathrm{mol} / \mathrm{cm}^{3}\right]$ are respectively the average and the maximal concentrations of lithium in the PE active-material.

-Electrode equilibrium potential: the electrode $O C P$ is an electric potential measured at zero current versus a reference electrode (electrode with a constant electric potential at equilibrium), (see Figure 3.a). Metal lithium electrode is mostly used as the reference electrode [24]. At zero current, the electric potential value of this reference electrode is $0 \mathrm{~V}$ compared to the couple $L i^{+} / L i$.

The electrodes $O C P$ of the LIBs vary with the lithiation rate non-linearly and with the electrode operation history [25] (Figure 3.b). The shape of $O C P$ curve is typically related to the active-material. As shown in Figure 3.b, for the graphite active-material, (which is the most used active-material of the negative electrode in the commercial LIBs), the shape of $O C P_{N E}$ curve has at least three plateaus. These plateaus correspond to the phase transitions of graphite. Each of these phase transitions theoretically appears at a given range of lithiation rate of graphite active-material [26]. For the $\mathrm{LiFePO}_{4}$ positive active-material, the shape of $O C P_{P E}$ curve typically exhibits a single plateau, which corresponds to its unique phase transition [27].

In LIBs, design factors such as the crystallinity rate or the purity level of the active-material can affect the shape of electrode $O C P$ curve, especially at the ends or the slopes between plateaus [28, 29, 30, 31, 32].

\subsubsection{Electrode balancing in a real Li-ion cell}

The concept of electrode balancing derives from the design rules of Li-ion cells [33, 34, 35, 36]. Thanks to these design rules, the three curves, (1) $O C P_{P E}$ curve, (2) $O C P_{N E}$ curve and (3) $O C V$ curve, can be positioned relatively to each other.

The shape of the battery $O C V$ curve is the combination of the $O C P$ curves of the two electrodes. From Figure 4 , it can be seen that (i) the three plateaus of the battery $O C V$ curve are from the $O C P$ curve of graphite activematerial, (ii) the $O C V$ slope at high values belongs to increasing $O C P$ of $\mathrm{LiFePO}_{4}$ active-material and (iii) the $O C V$ slope at low values is for both $O C P s$ activematerials.

Note that when the battery $S o C$ increases (during battery charging), the NE lithiation rate $x$ also increases, whereas the PE lithiation rate $y$ decreases. This is because of the transfer of lithium ions from the positive electrode to the negative electrode during battery charging. The reverse process occurs when the battery $S o C$ decreases during discharge. As a result, the curve of $O C P_{P E}$ is reversed in Figure 2 compared to Figure 3. The maximum number of exchanged lithium ions between both electrodes defines the battery capacity $\left(C_{\text {bat }}\right.$ [Ah]). The latter is measured by fully discharging or charging the battery at a reference constant-current and a reference temperature (temperature of the battery environment). The fully discharged and charged states of the battery correspond respectively to the minimum and the maximum limits of the battery voltage. These limits 

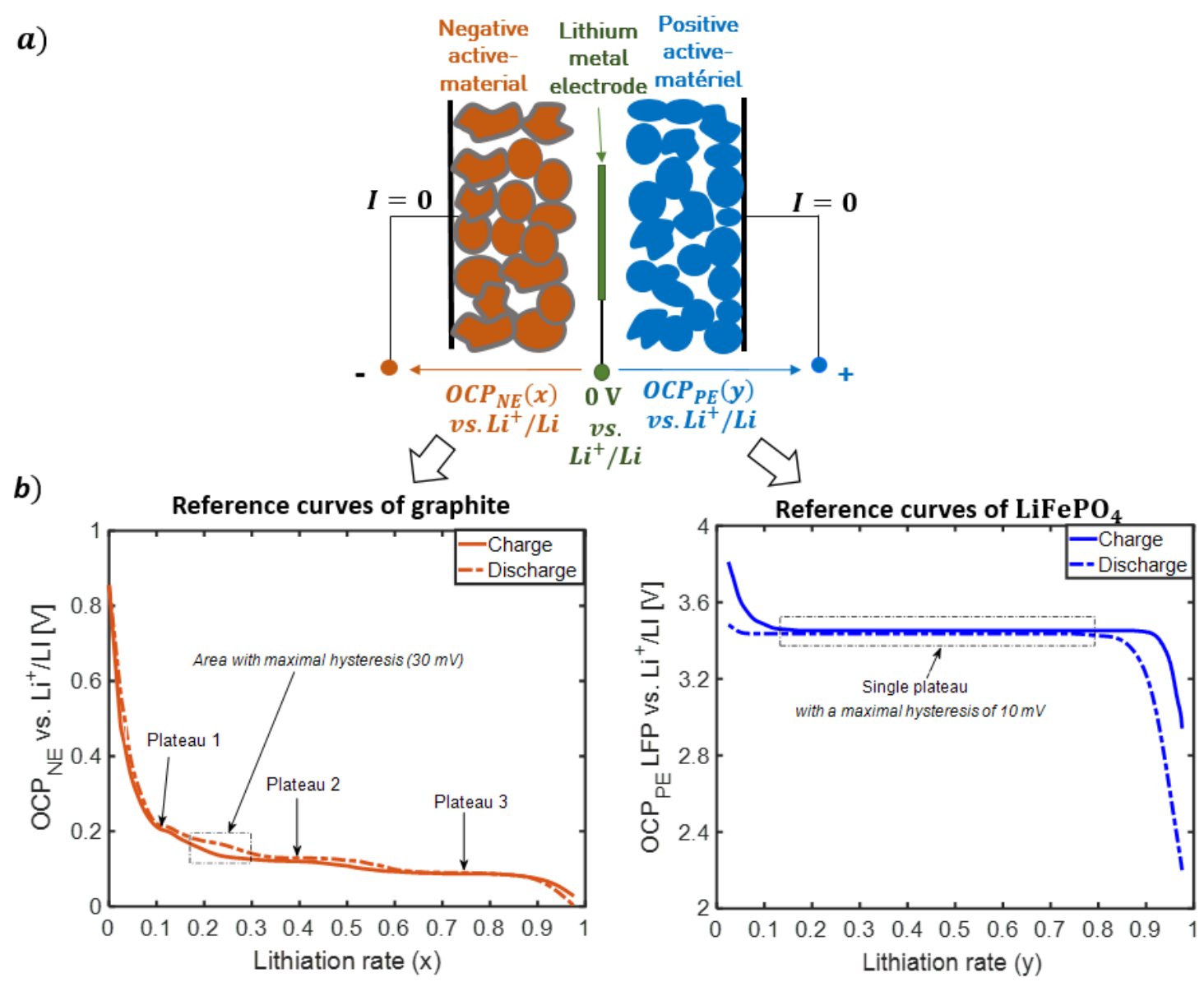

Figure 3: a) Schematic of electrodes $O C P$ measurement vs. lithium metal reference electrode. b) $O C P$ curves of half-cell graphite electrode vs. metal lithium electrode (at left) and half-cell $\mathrm{LiFePO}_{4}$ electrode vs. metal lithium electrode (at right). The data in these curves are issued from [23].

correspond respectively to $2.5 \mathrm{~V}$ and $3.6 \mathrm{~V}$ in Figure 4.

As it is represented in Figure 4, when the battery is fully charged, the lithiation rate in PE is close to zero. And, when the battery is fully discharged, the lithiation rate in $\mathrm{NE}$ is also close to zero $[18,37]$. Here we call $y_{b a t, 100 \%}$ is the lithiation rate of PE when the battery is fully charged, $\left(S o C=C_{b a t}\right)$ and $x_{b a t, 0 \%}$ is the lithiation rate of the NE when the battery is fully discharged, $(S \circ C=0 \mathrm{Ah})$.

In Figure 4, the curve of $O C P_{N E}$ is larger than the curve of $O C P_{P E}$. This is because in a real LIB, the graphite negative electrode is typically designed with a larger capacity than the positive electrode [14, 33, 37]. The oversized capacity of the graphite electrode prevents its lithiation rate $x$ to reach 1 . That avoids its $O C P$ to reach $0 \mathrm{~V}$ vs. $L^{+} / L i$, which is the equilibrium potential value of the unwanted reaction of the LIBs called lithium plating $[38,39]$. $C_{P E}[\mathrm{Ah}]$ and $C_{N E}[\mathrm{Ah}]$ represent respectively the capacities of the positive electrode $\left(\mathrm{LiFePO}_{4}\right)$ and the negative electrode (graphite). The capacity of each electrode is related to the elec- trode maximal concentration by the following equations $[23,7]$ :

$$
\begin{aligned}
& C_{N E}=F \cdot A \cdot L_{N E} \cdot \varepsilon_{N E} \cdot c_{s, N E}^{\max } \\
& C_{P E}=F \cdot A \cdot L_{P E} \cdot \varepsilon_{P E} \cdot c_{s, P E}^{\max }
\end{aligned}
$$

where $F[\mathrm{C} / \mathrm{mol}]$ is the Faraday constant, $A\left[\mathrm{~cm}^{2}\right]$ is the battery area, $L_{P E}[\mathrm{~cm}]$ and $L_{N E}[\mathrm{~cm}]$ are respectively the thickness of PE and NE, $\varepsilon_{P E}$ and $\varepsilon_{N E}$ are their respective porosities. From Equations (4) and (5), it can be observed that the capacity of each electrode includes its specific design and electrochemical parameters. In addition, the theoretical specific capacity of $\mathrm{LiFePO}_{4}$ active-material is $0.170 \mathrm{Ah} / \mathrm{g}$ [27]. For graphite active-material, it is $0.372 \mathrm{Ah} / \mathrm{g}$ [40]. Consequently, assuming that the electrode capacity can be determined, the amount of active-material in grams for $\mathrm{LiFePO}_{4}$ and graphite electrodes of a LIB can be respectively estimated as follows: $m_{P E}=C_{P E} / 0.170 \mathrm{~g}$ and $m_{N E}=C_{N E} / 0.372 \mathrm{~g}$.

This shows that an electrode capacity can be a useful 


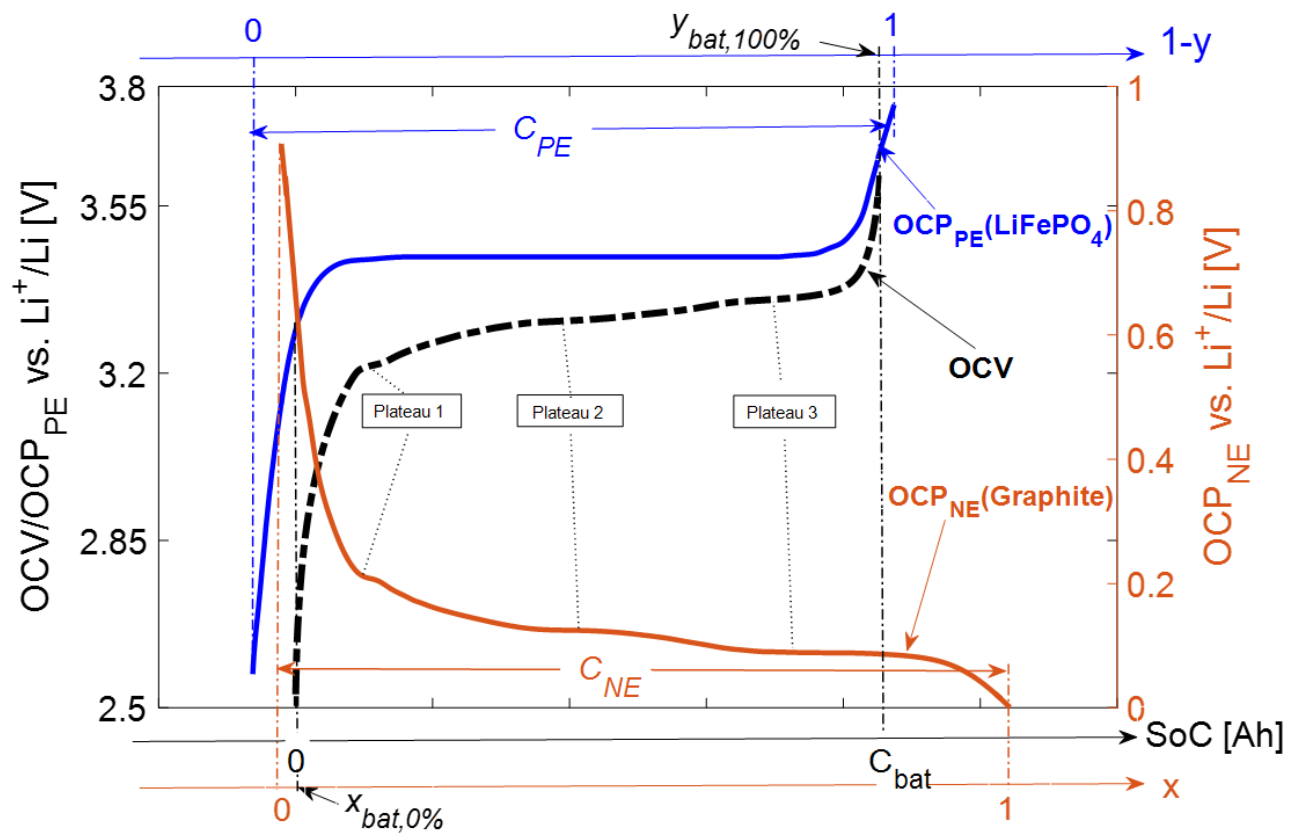

Figure 4: Positions of $O C P_{P E}, O C P_{N E}$ and $O C V$ curves in a real LIB: illustration with a $\mathrm{LiFePO}_{4} /$ graphite LIB [18, 37]. Color should be used for this figure in print.

and reliable parameter for the quantification of the electrode state of health.

Relationships between battery SoC and electrode lithiation rates: From Figure 4, the relationships between the battery $S o C$ and individual electrode lithiation rates, $x$ and $y$, can be established (Equations (6) and (7)).

$$
\begin{gathered}
S o C=\left(x-x_{b a t, 0 \%}\right) C_{N E} \\
C_{b a t}-S o C=\left(y-y_{b a t, 100 \%}\right) C_{P E}
\end{gathered}
$$

By expressing $x$ and $y$ based on $S o C$ and other parameters, we obtain Equations (8) and (9).

$$
\begin{aligned}
& x=x_{b a t, 0 \%}+\frac{S o C}{C_{N E}} \\
& y=y_{b a t, 100 \%}+\frac{C_{b a t}-S o C}{C_{P E}}
\end{aligned}
$$

By introducing Equations (8) and (9) in Equation (3), the electrode $O C P$ of a LIB can be mathematically expressed as functions of the battery $S o C$ (Equation (10)).

$$
\begin{array}{r}
O C V(S o C)=O C P_{P E}\left(y_{b a t, 100 \%}+\frac{C_{b a t}-S o C}{C_{P E}}\right)- \\
O C P_{N E}\left(x_{b a t, 0 \%}+\frac{S o C}{C_{N E}}\right)
\end{array}
$$

In addition, by mixing Equations (1) and (10), the battery $p O C V$ can be expressed as follows:

$$
\begin{aligned}
p O C V(S o C)= & O C P_{P E}\left(y_{b a t, 100 \%}+\frac{C_{b a t}-S o C}{C_{P E}}\right)- \\
& O C P_{N E}\left(x_{b a t, 0 \%}+\frac{S o C}{C_{N E}}\right)+\eta(S o C)
\end{aligned}
$$

With the two last equations, we have respectively the battery $O C V$ (Equation (10)) and pOCV (Equation (11)) models, which contain the equilibrium potentials of both electrodes, their capacities and their minimal lithiation rates.

\section{Method for electrode balancing identification}

\subsection{Method assumptions}

In the previous section, it is clearly established that the quantities related to the electrode properties that we need to determine, (as a reminder, the positive and negative electrode capacities and the equilibrium potential curve of each electrode as a function of the battery state of charge), are all included in battery $p O C V$ curve that can be measured. For the determination of these parameters, Han et al. [4] combined the battery $p O C V$ measurements for charge with the corresponding reference curves of both electrodes $O C P$. Actually, since the overvoltage included in the charge (or discharge) $\mathrm{pOCV}$ 
measurements is difficult to estimate properly, it is expected that this leads to a considerable bias on the results. Here we propose to associate the average curve between the discharge $p O C V$ and charge $p O C V$ of the battery with the average reference curves of the electrodes $O C P$. It is assumed that the average curve of the $p O C V$ is equal to the average curve of $O C V$ (Equation (12)). In other words, the contribution of the average overvoltage $\eta_{a v g}$ in the $p O C V_{a v g}$ is expected to be considerably reduced so that it can be neglected. This is because the charge overvoltage $\eta_{\text {cha }}$ and discharge overvoltage $\eta_{\text {dis }}$ are symmetrical, $\left(\eta_{\text {cha }} \simeq-\eta_{\text {dis }}\right.$, with $\eta_{\text {cha }}>0$ and $\eta_{\text {dis }}<0$ ).

$$
\begin{aligned}
p O C V_{a v g} & =\frac{p O C V_{c h a}+p O C V_{d i s}}{2} \\
& =\frac{O C V_{c h a}+O C V_{d i s}}{2}+\frac{\eta_{c h a}+\eta_{d i s}}{2} \\
& =\frac{O C V_{c h a}+O C V_{d i s}}{2}+\frac{\eta_{c h a}+\eta_{d i s}}{2} \\
& =O C V_{a v g}+\eta_{a v g} \\
& \simeq O C V_{a v g}
\end{aligned}
$$

The low contribution of average overvoltage $\eta_{\text {avg }}$ can further be analyzed by observing the experimental data of the $p O C V(\mathrm{C} / 50)$ and the $O C V$ of a $\mathrm{LiFePO}_{4} /$ graphite LIB in Figure 5. From Figure 5.b,

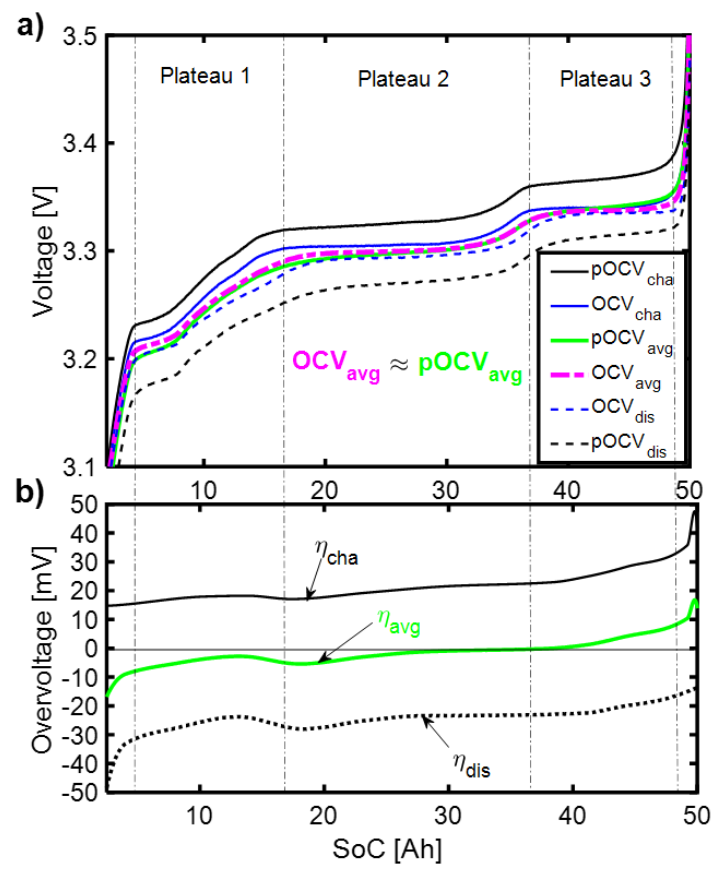

Figure 5: a) Curves of $p O C V(\mathrm{C} / 50)$ and $O C V$ for discharge, charge and the average between both of a real $\mathrm{LiFePO}_{4} /$ graphite LIB. b) The corresponding overvoltages. Color should be used for this figure in print it can be observed that $\eta_{\text {dis }}$ tends to decrease towards low $S o C$ and $\eta_{\text {cha }}$ tends to increase towards high $S o C s$. As a consequence, $\eta_{\text {avg }}$ tends also to increase from both low and high battery $S o C$. Focusing only on the region including the three plateaus, where useful information can be extracted, $\eta_{\text {avg }}$ is at least three times smaller than discharge overvoltage $\eta_{\text {dis }}$ and charge overvoltage $\eta_{c h a}$. Furthermore, one can observe the apparent shifts of plateaus between the $p O C V$ and the $O C V$ curves for both discharge and charge curves in Figure 5.a. These shifts are considerably reduced by comparing the $p O C V_{\text {avg }}$ and $O C V_{\text {avg }}$ curves. This confirms the interest of using the average $p O C V$ curve with the average reference curves of the electrodes $O C P$ for better accuracy.

\subsection{Optimization problem and algorithm}

Before presenting the optimization problem, we would like first to define the input data of the proposed method. These inputs are defined as follow:

- the $p O C V$ measurements versus $S o C$ of the battery for discharge and charge, which allow getting the average $O C V$ curve: $O C V_{a v g}^{\text {meas }}=f(S o C)$.

- the reference $O C P$ curves of both electrodes (issued from the literature), for discharge and charge, which allow having their respective average curves: $O C P_{P E \text {,avg }}^{r e f}=f\left(y^{r e f}\right)$ and $O C P_{N E \text {,avg }}^{r e f}=$ $f\left(x^{r e f}\right)$. The reference $O C P$ curves of the graphite and the $\mathrm{LiFePO}_{4}$ electrodes issued from the literature are considered to be the same with the "true" $O C P$ curve of each electrode in a real $\mathrm{LiFePO}_{4} /$ graphite LIB, because the $O C P$ is an intrinsic property of an electrode active-material.

The objective cost function $f$ for identification of the electrodes balancing can be defined as follow:

$$
\begin{aligned}
\min f_{\theta} & =O C V_{\text {avg }}^{e s t}(S o C)-O C V_{\text {avg }}^{\text {meas }}(S o C) \\
& =\underbrace{\left[O C P_{P E, \text { avg }}^{r e f}(y)-O C P_{N E, \text { avg }}^{r e f}(x)\right]}_{O C V_{\text {avg }}^{\text {est }}(S o C)}-O C V_{\text {avg }}^{\text {meas }}(S o C)
\end{aligned}
$$

with, $\theta=\left[x_{b a t, 0 \%}, y_{b a t, 100 \%}, C_{N E}, C_{P E}\right]$ subjects to the following constraints:

$\left\{\begin{array}{l}x=x_{b a t, 0 \%}+S o C / C_{N E} \\ y=y_{b a t, 100 \%}+\left(C_{b a t}-S o C\right) / C_{P E} \\ \text { given } C_{b a t}\end{array}\right.$

The different steps of the algorithm are illustrated in Figure 6. The nonlinear least square optimization function lsqnonlin of Matlab software has been used. 


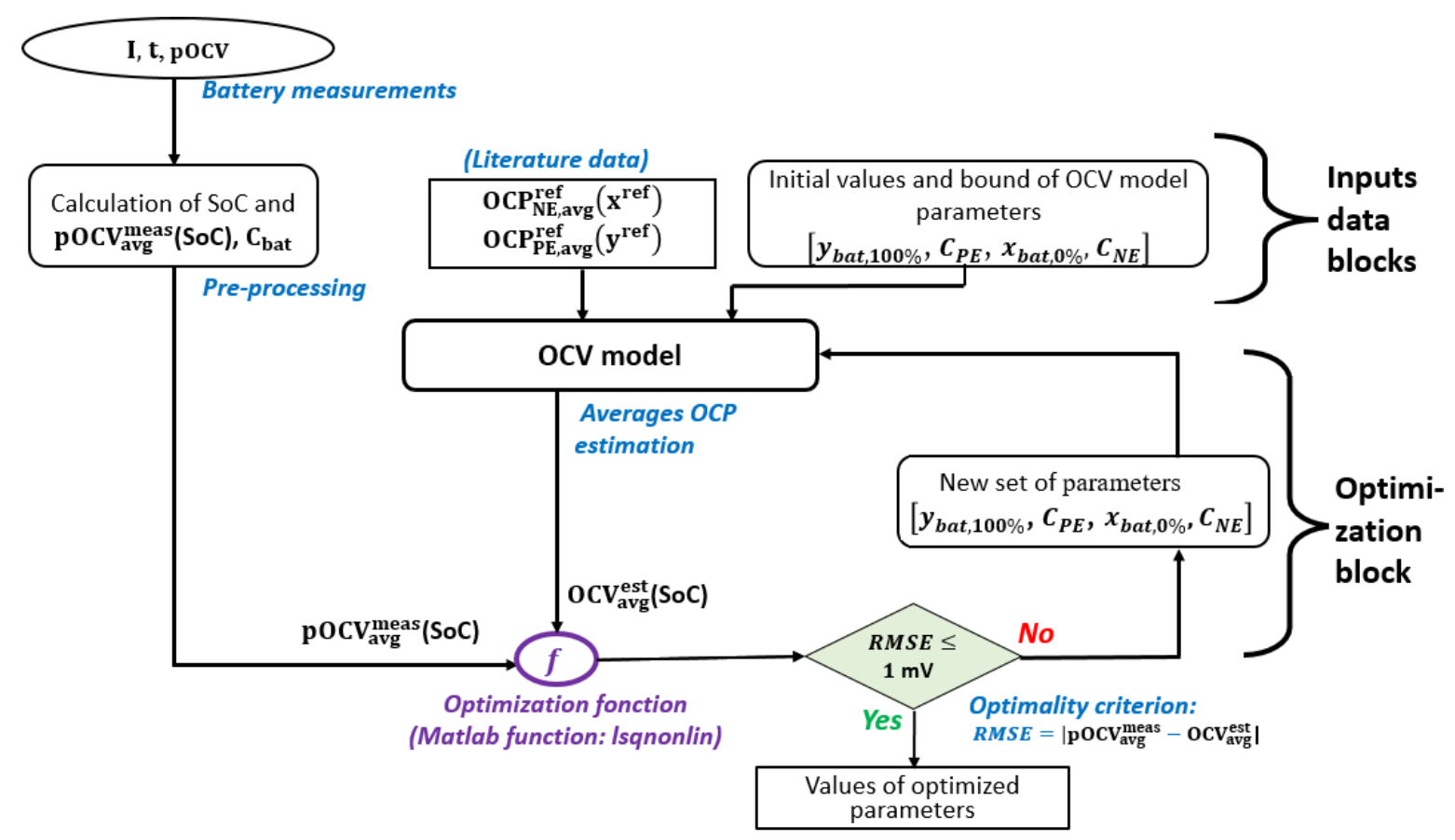

Figure 6: Algorithm flowchart of the electrodes balancing identification, (RMS E: Root Mean Square Error).

The parameters $x_{b a t, 0 \%}$ and, $y_{b a t, 100 \%}$ were bounded between 0 and 0.2 . Both parameters were initialized to 0. $C_{N E}$ and $C_{P E}$ were respectively initialized to $1.4 C_{b a t}$ and $C_{b a t}$, and bounded as follow: $C_{b a t}<C_{P E}<1.1 C_{\text {nom }}$ and $C_{b a t}<C_{N E} \leq 1.4 C_{n o m}$. $C_{n o m}$ is the battery nominal capacity given by the manufacturer.

\section{Method validation}

\section{1. pOCV measurement tests}

In order to evaluate the proposed method, the study was carried out on a cylindrical (size 22650) A123Systems cell with a nominal capacity $2.3 \mathrm{Ah}$ according to the manufacturer $\left(C_{n o m}\right)$. The cell is made of a graphite negative electrode and a $\mathrm{LiFePO}_{4}$ positive electrode. The $p O C V$ tests for charge at $\mathrm{C} / 25$ and discharge at $\mathrm{C} / 25(92 \mathrm{~mA})$ revealed a cell capacity $C_{b a t}$ corresponding to $2.13 \mathrm{Ah}$. These tests were performed with a Bio-Logic system VSP-300 with a 2 A booster. The cut-off voltages of the cell were set to $2.5 \mathrm{~V}$ and 3.6 $\mathrm{V}$. The cell was tested in a climatic chamber in which the temperature was set at $25^{\circ} \mathrm{C}$.

\subsection{Method results}

Figure 7 shows the results of the method on the studied cell. The computational time to obtain the results was $2 \mathrm{~s}$. The measured average $O C V\left(O C V_{a v g}^{\text {meas }}\right)$ corresponds to the region between the two discontinuous vertical lines. The estimated average $O C V\left(O C V_{a v g}^{e s t}\right)$ represents the difference between the $O C P_{a v g, P E}$ and $O C P_{a v g, N E}$ curves in this region. By comparing $O C V_{a v g}^{e s t}$ and $O C V_{a v g}^{\text {meas }}$ in the three-plateaus region, it can be observed that $O C V_{\text {avg }}^{\text {est }}$ is overestimated towards low battery $S o C$ s (see the dotted rectangle in Figure 7). The maximal deviation to this region is $11 \mathrm{mV}$. Note that in this area the hysteresis of graphite reaches its maximum value, (which is $30 \mathrm{mV}$ see Figure 3.b). This could explain the overestimation of $O C V_{a v g}^{e s t}$. Basically, the $O C V_{\text {avg }}^{\text {est }}$ curve has the same shape as the $O C V_{\text {avg }}^{\text {meas }}$ curve. Both curves are close, with a root mean square error $(R M S E)$ of $6 \mathrm{mV}$ in the three-plateaus region. This $R M S E$ is acceptable.

The estimated values of the four fitting parameters with their initializations have been reported in Table 1 . It can be seen that the estimated values are different from the initial values. The estimated minimal lithiation rates $x_{b a t, 0 \%}$ and $y_{b a t, 100 \%}$ are very close to 0 .

With the optimization algorithm, a weighting process was added in order to achieve better accuracy of fitting on the plateaus rather than at the filling rates $x_{b a t, 0 \%}$ and $y_{b a t, 100 \%}$. This is because the plateaus are linked to the modification of the graphite active-material structure. These plateaus provide relevant information about the theoretical capacity of the graphite electrode. For example, as it is shown in Figure 8, the transition between Plateau 2 and Plateau 3 corresponds to the evolution of 


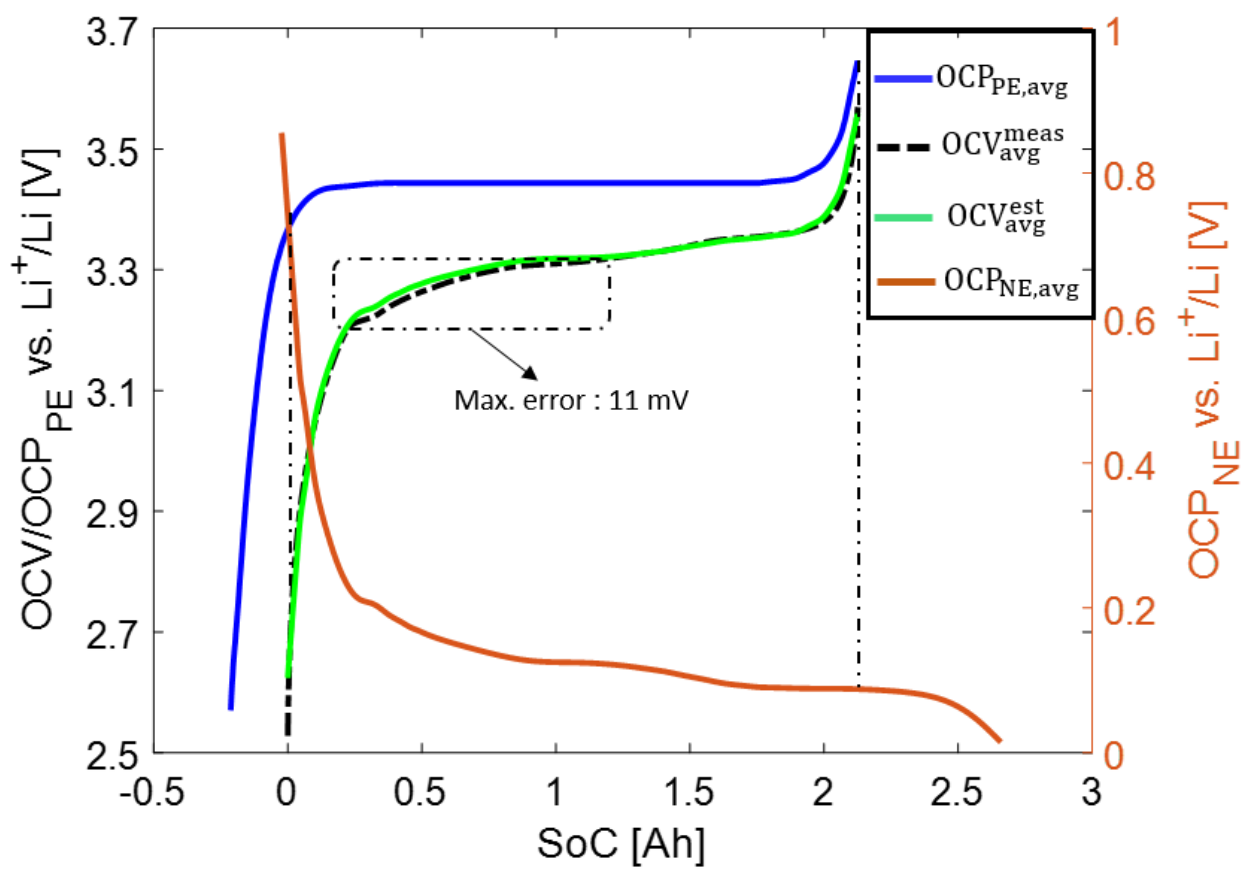

Figure 7: Method results on the studied cell with measured battery capacity $C_{b a t}=2.13 \mathrm{Ah}$. Color should be used for this figure in print.

$L i C_{12}$ to $L_{i C_{6}}$. This transition corresponds to half the theoretical capacity of the graphite electrode [41].

\begin{tabular}{ccccc} 
& $x_{\text {bat }, 0 \%}$ & $y_{\text {bat }, 100 \%}$ & $C_{N E}[A h]$ & $C_{P E}[A h]$ \\
\hline Initial. & 0 & 0 & 2.98 & 2.13 \\
\hline Estimat. & 0.0083 & 0 & 2.75 & 2.34 \\
\hline
\end{tabular}

Table 1: Estimated parameters with the proposed method for the A123Systems cell with $C_{b a t}=2.13$ Ah.

The estimated electrode capacities $C_{P E}$ and $C_{N E}$ are respectively $10 \%$ and $30 \%$ larger than the measured battery capacity $C_{b a t}$, which means that the positive and negative active-materials are respectively unused at 10 $\%$ and $30 \%$ in this cell.

Based on the graphite active-material characteristics and the cell $O C V_{a v g}^{\text {meas }}$ curve (Figure 8), the theoretical capacity of the graphite electrode $C_{N E \text {,theo }}$ has been estimated at $2.72 \mathrm{Ah}$, which is of the same order of magnitude of the graphite electrode capacity obtained by fitting. For the $\mathrm{LiFePO}_{4}$ electrode, the error on the estimated capacity is believed to be high, because the single transition between its phases, $\left(\mathrm{Li}_{\mathrm{y}} \mathrm{FePO}_{4}\right.$ and $\left.\mathrm{FePO}_{4}\right)$, does not provide information about its capacity. However, design rules applied to commercial cells limit the ratio of $\mathrm{LiFePO}_{4}$ electrode capacity to graphite electrode capacity. A low $C_{N E} / C_{P E}$ ratio (close to $100 \%$ ) could indeed lead to lithium plating on the graphite electrode [42], while a very high one could promote a loss of battery capacity [33]. According Berg [43], in com-

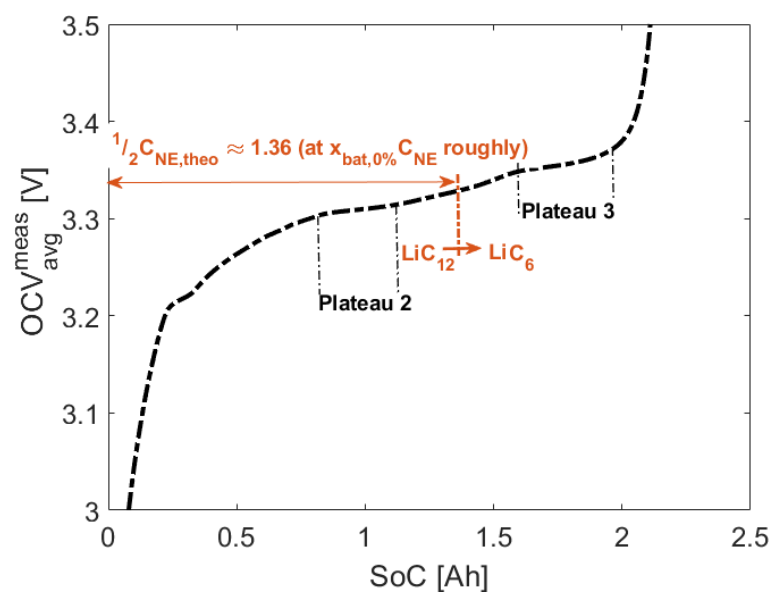

Figure 8: Estimation of the theoretical capacity of the graphite electrode from the average $O C V$ curve.

mercial cells, the $C_{N E} / C_{P E}$ ratio is typically around 120 $\%$. Based on the estimated electrode capacities, the $C_{N E} / C_{P E}$ ratio yields $117.5 \%$.

For positive active-materials with steeper $O C P$ curves than the one of the $\mathrm{LiFePO}_{4}$, a better estimation of the positive electrode capacity is expected.

\subsection{Comparison of the proposed method with existing method}

To assess the accuracy of the proposed approach, the previous results are compared with the approach used 


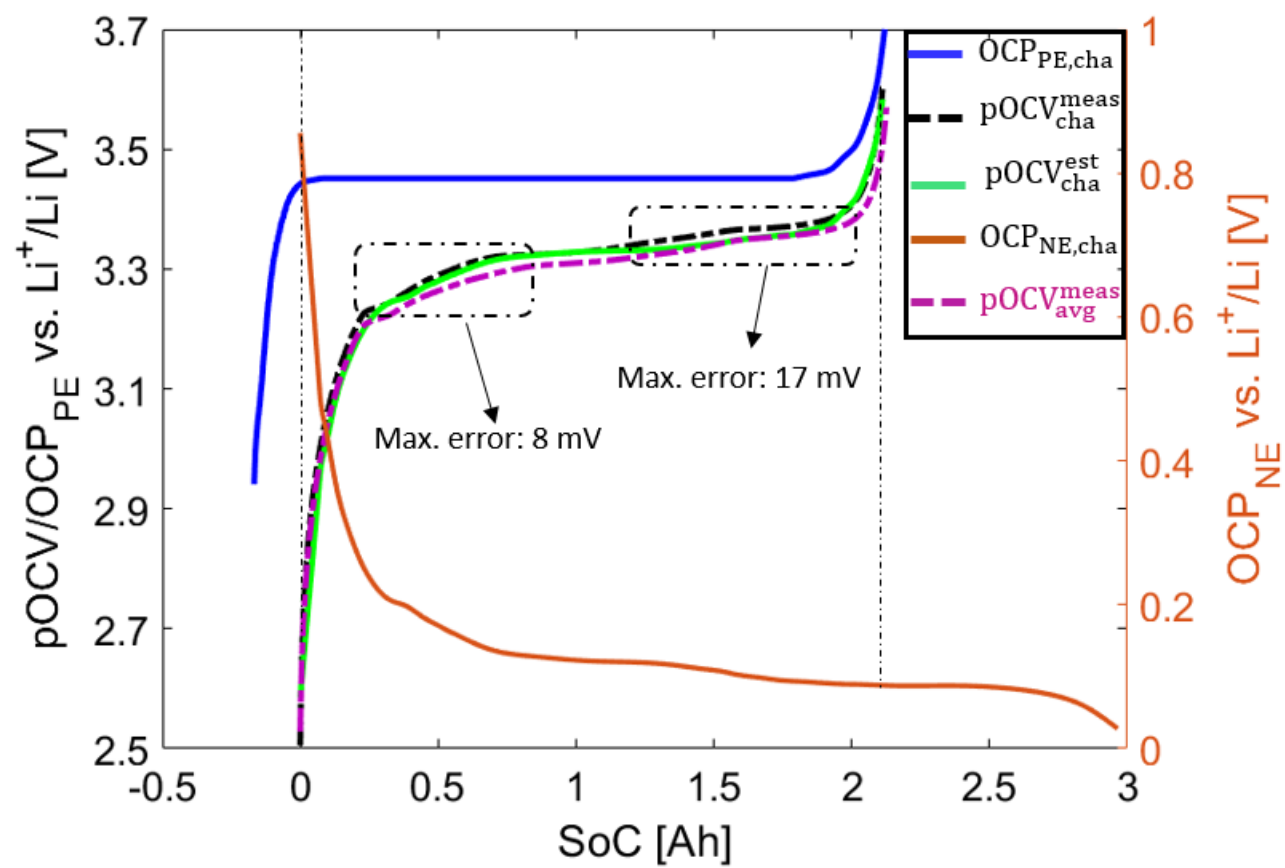

Figure 9: Results obtained by using the existing method on A123Systems cell. Color should be used for this figure in print.

by authors in $[4,5,6]$. This existing method used the measured battery $p O C V$ in charge $\left(p O C V_{c h a}^{\text {meas }}\right)$. By adopting the existing approach, a $p O C V$ model is used and the cell overvoltage $\eta_{\text {cha }}$ is defined as the product of current $I$ and cell internal resistance $R$. The overvoltage contribution is determined by treating $R$ as one of the 5 fitting parameters, which are presented in objective cost function $g$ in Equation (14).

$\min g_{\left[x_{b a t, 0 \%}, y_{b a t, 100 \%}, C_{N E}, C_{P E}, R\right]}=p O C V_{c h a}^{e s t}-p O C V_{c h a}^{\text {meas }}$

with, $p O C V_{c h a}^{e s t}=\left[O C P_{P E, c h a}^{r e f}-O C P_{N E, c h a}^{r e f}+I R\right]$.

The results obtained by using the existing approach are shown in Figure 9, in which the $p O C V_{a v g}^{\text {meas }}$ curve is also represented. The estimated curve $p O C V_{c h a}^{e s t}$ is slightly shifted on both axes due to the overvoltage contribution. Moreover, the estimated curve $p O C V_{c h a}^{e s t}$ is underestimated around the two extreme plateaus (see rectangles in Figure 9).

The estimated parameters obtained with the existing approach are reported in Table 2, in which the previous results obtained with the new approach are also presented. For the existing approach, we found that by changing different values of the internal resistance $R$ (between 0 and $100 \mathrm{~m} \Omega$ ), the values of the four other parameters $\left(x_{b a t, 0 \%}, y_{b a t, 100 \%}, C_{N E}, C_{P E}\right)$ do not change and the quality of fitting was also not improved. This is because the overvoltage $\eta_{c h a}=R I$ is considered constant with

\begin{tabular}{ccc} 
& New method & Existing method \\
\hline$x_{\text {bat }, 0 \%}$ & 0.0083 & 0 \\
\hline$y_{\text {bat }, 100 \%}$ & 0 & 0.0173 \\
\hline$C_{N E}[A h]$ & 2.75 & 3.04 \\
\hline$C_{P E}[A h]$ & 2.34 & 2.32 \\
\hline$R[m \Omega]$ & N/A & 10
\end{tabular}

Table 2: Comparison between the parameters obtained with the existing approach and the new approach.

respect to the battery $S o C$.

Given the above, the overvoltage included in the measured battery $p O C V$ is not well taken into account with the existing approach. As a consequence, this overvoltage leads to a bias on the estimated parameters, especially the electrode capacities.

From Table 2, it can be observed that the electrode capacities and lithiation rates obtained with the existing approach are different from those obtained with the new approach. A significant difference is observed on $C_{N E}$, with a capacity $11 \%$ greater than the one obtained with the new method. The $C_{P E}$ obtained with both approaches are very close.

\section{Robustness of the proposed method}

The robustness of the proposed method was studied on an aged A123Systems cell with a measured capacity $C_{b a t}=1.99$ Ah vs. 2.13 Ah for the "new" cell. The 


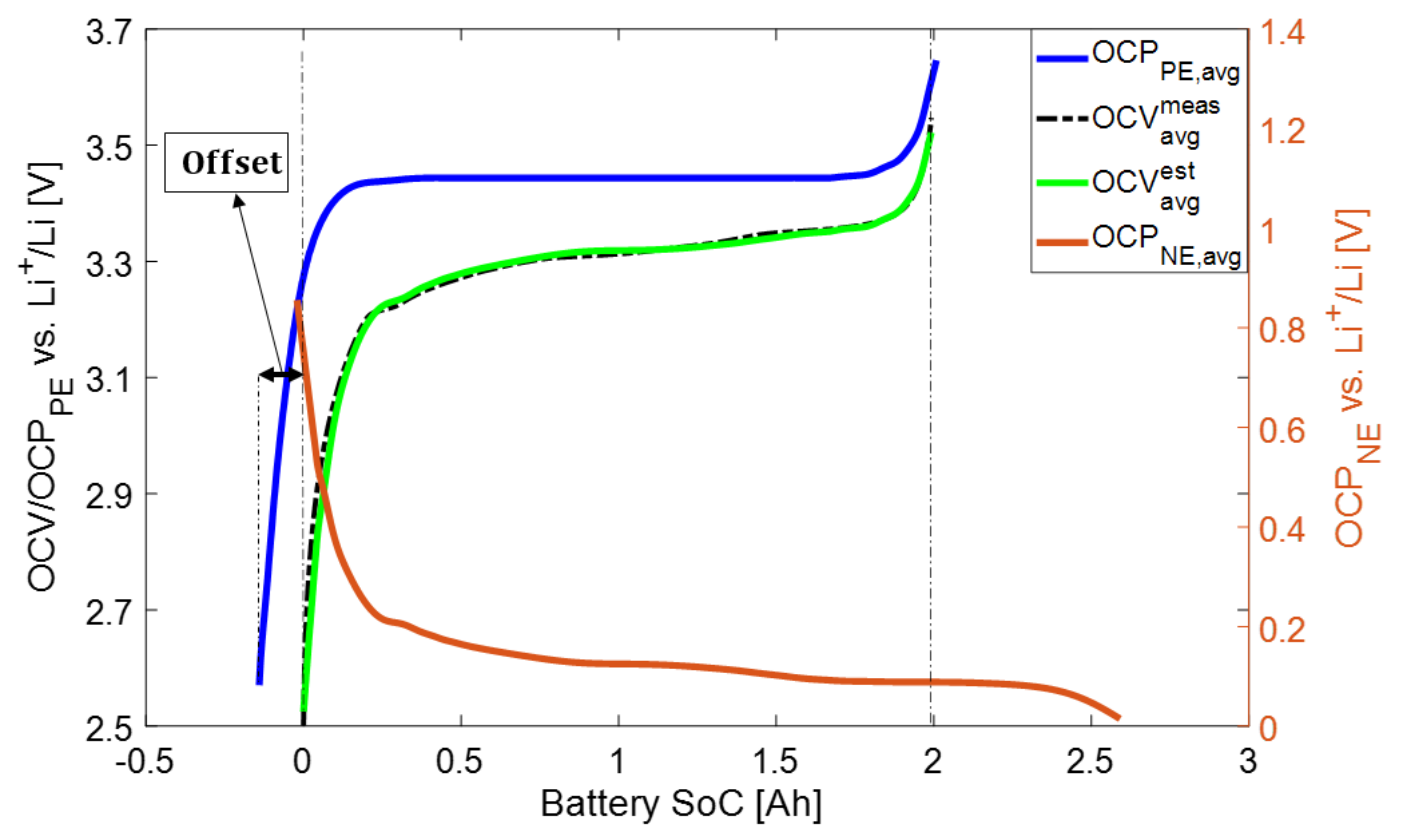

Figure 10: Method results on the aged cell A123Systems with measured battery capacity $C_{b a t}=1.99$ Ah.

experimental tests on the aged cell were performed in the same conditions as described in the previous section.

The algorithm was first ran by keeping the same initialization values for the four fitting parameters as for the "new" A123Systems cell. For the aged cell, the $O C V_{\text {avg }}^{e s t}$ and the $O C V_{\text {avg }}^{\text {meas }}$ curves are very close $(R M S E=2 \mathrm{mV})$, as it can be observed in Figure 10 . The estimated parameters reported in Table 3 are different compared to the parameters of the "new" cell (Table 1). Actually, the aged cell has a lower $x_{b a t, 0 \%}$, higher $y_{b a t, 100 \%}$, lower $C_{N E}$ and lower $C_{P E}$ than for the "new" cell.

The algorithm was then ran with different initializations for each of four fitting parameters. For a given parameter, the study was carried out by changing its initialization and by keeping the initialization of the other parameters as previously. It was found that the initialization of $x_{b a t, 0 \%}$ and $y_{b a t, 100 \%}$ to any value between 0 and 1 does not impact the convergence of the above results (Table 3 ). For the $C_{P E}$ and $C_{N E}$, the convergence to these results were respectively obtained with different initialization values within the following ranges: $C_{b a t} \leq$ $C_{P E} \leq 1.1 C_{n o m}$ and $C_{N E} \geq C_{b a t}$. Ageing processes lead to loss of cell capacity $C_{b a t}$ and changes of the shape of the cell $O C V$ curve. Derivative methods like differential voltage analysis (DVA) or incremental capacity analysis (ICA) are widely used to study theses changes $[4,6,7,16,18]$. By tracking the changes in $O C V_{a v g}^{\text {meas }}$ curve at any state of health of the cell with these deriva-

\begin{tabular}{ccccc}
\cline { 2 - 5 } & $x_{\text {bat }, 0 \%}$ & $y_{\text {bat }, 100 \%}$ & $C_{N E}[\mathrm{Ah}]$ & $C_{P E}[\mathrm{Ah}]$ \\
\hline Initial. & 0 & 0 & 2.98 & 2.13 \\
\hline Estimat. & 0.0078 & 0.0076 & 2.68 & 2.15 \\
\hline
\end{tabular}

Table 3: Estimated parameters for the aged A123Systems cell with $C_{\text {bat }}=1.99 \mathrm{Ah}$

tive methods, it is possible to reproduce these changes with the optimization algorithm. This could be achieved (i) by ensuring the increase in the offset between the two $O C P$ curves (related to $C_{b a t}$ ) (Figure 10) or (ii) by ensuring that the capacity of one or both electrodes decreases. The proposed method can then be used as a non-invasive tool that quantifies the state of health of each electrode of the battery.

The ageing processes inside batteries lead to three main consequences called degradation modes [43]. Considering $t_{0}$ as the initial state and $t_{1}$ as the aged state, the cells degradation modes and their links with the estimated parameters are as follows:

- The loss of lithium inventory LLI (or loss of lithium exchanged). This degradation mode results in the increase of the offset between the $O C P$ curves of negative and positive electrodes (see Figure 10). This would lead to a decrease of the $C_{b a t}$ parameter only.

$$
L L I[A h]=C_{b a t}\left(t_{0}\right)-C_{b a t}\left(t_{1}\right) .
$$

- The loss of active-material of the negative elec- 
trode $L A M_{N E} . L A M_{N E}$ is related to the decrease in capacity of the negative electrode.

$$
L A M_{N E}[A h]=C_{N E}\left(t_{0}\right)-C_{N E}\left(t_{1}\right) .
$$

- The loss of active-material of positive electrode $L A M_{P E}$, which is related to the decrease in capacity of the positive electrode.

$$
L A M_{P E}[A h]=C_{P E}\left(t_{0}\right)-C_{P E}\left(t_{1}\right) .
$$

The application of the proposed method to the battery diagnostic ends is beyond the present scope and will be studied in the future.

\section{Conclusions}

A non-invasive method to determine the electrode balancing, namely the state parameters of positive and negative electrodes separately in commercial LIBs, has been presented. These state quantities were defined by (i) the electrode capacity and (ii) the electrode equilibrium potential curves as functions of battery state of charge.

The proposed method has been applied to the characteristics of the battery voltage curve for a low constantcurrent. The mathematical relationships between the battery voltage and these state quantities were established. We propose to determine these quantities by fitting the average curve of the battery voltage measurements at low current with the average reference curves of equilibrium potentials of the battery electrodes.

The proposed method was used on a commercial $\mathrm{LiFePO}_{4} /$ graphite cell. The reference curves of equilibrium potentials of the battery electrodes are taken from the literature. The results obtained are satisfactory in terms of fitting quality and the magnitude order of the state quantities of the electrodes.

Furthermore, the access of the individual curves of electrode equilibrium potentials as functions of the battery state of charge is the first step towards the implementation of a non-invasive tool for the Li-ion batteries fast recharging optimization. The second step that we are working on is the non-invasive separation of the contributions of both electrodes on the battery overvoltage for high charging currents. This will help to get a non-invasive tool for monitoring the electrical potential of the graphite electrode during fast recharging to avoid the unwanted reaction of lithium plating.

\section{Acknowledgements}

We thank the ministry of national education of France and the region of Hauts-de-France for granting this $\mathrm{PhD}$ research work.

\section{References}

[1] J. Janek, Wolfgang G. Zeier. A solid future for battery development. Nat. Energy, vol. 1, pp. 16141, 2016.

[2] W. Waag, C. Fleischer, D. U. Sauer. Critical review of the methods for monitoring of lithium-ion batteries in electric and hybrid vehicles. J. Power Sources, vol. 258, pp 321-339, 2014.

[3] J. Vetter and P. Novák, M.R. Wagner, C. Veit, K.-C. Möller, J.O. Besenhard, M. Winter, M. Wohlfahrt-Mehrens, C. Vogler, A. Hammouche. Ageing mechanisms in lithium-ion batteries. J. Power Sources, vol. 147,(1), pp. 269-281, 2005.

[4] X. Han, M. Ouyang, L. Lu, J. Li, Y. Zheng, Z. Li. A comparative study of commercial lithium-ion battery cycle life in electrical vehicle: Aging mechanism identification. J. Power Source, vol. 251, pp. 38-54, 2014.

[5] X. Feng, J. Sun, M. Ouyang, X. He, L. Lu, X. Han, Mou Fang, H. Peng. Characterization of large format lithium ion battery exposed to extremely high temperature. J. Power Source, vol. 272, 457-467, 2014.

[6] M. Ouyang, Z. Chu, L. Lu, J. Li, X. Han, X. Feng, G. Liu, "Low temperature aging mechanism identification and lithium deposition in a large format lithium iron phosphate battery for different charge profiles.”, J. Power Source, 286, 309-320, 2015.

[7] T. Lu, Y. Luo, Y. Zhang,W. Luo, L. Yan, J. Xie, "Degradation Analysis of Commercial Lithium-Ion Battery in Long-Term Storage.”, J. Electro. Soc., vol. 164 (4), A775-A784, 2017.

[8] S. Schindler, M. A. Danzer. A novel mechanistic modeling framework for analysis of electrode balancing and degradation modes in commercial lithium-ion cells. J. Power Sources vol. 343, 226-236, 2017.

[9] A. Barai, K. Uddin, M. Dubarry c , L. Somerville, A. McGordon, P. Jennings, I. Bloom. A comparison of methodologies for the non-invasive characterisation of commercial Li-ion cells. Progress in Energy and Combustion Science, vol. 72, 1-31, 2019.

[10] E. McTurk, C. R. Birkl, M. R. Roberts, D. A. Howey, P. G. Bruce. Minimally Invasive Insertion of Reference Electrodes into Commercial Lithium-Ion Pouch Cells. ECS Electrochem. Lett, vol. 4 (12), A145-A147, 2015.

[11] P. Liu, J. Wang, J. Hicks-Garner, E. Sherman, S. Soukiazian, M. Verbrugge, H. Tataria, J. Musser, P. Finamore. Aging Mechanisms of $\mathrm{LiFePO}_{4}$ Batteries Deduced by Electrochemical and Structural Analyses. J. Power Sources, vol. 157, (4), A499A507, 2010.

[12] R. Scipioni, P. S. Jørgensen, C. Graves, J. Hjelm, S. H. Jensen, A Physically-Based Equivalent Circuit Model for the Impedance of a $\mathrm{LiFePO}_{4} / \mathrm{Graphite} 26650$ Cylindrical Cell. J. Electrochem. Soc., 164, (9), A2017-A2030, 2017.

[13] E. Pradda, Aging modeling and lifetime optimization of Li-ion $\mathrm{LiFePO}_{4}$-graphite batteries according to the vehicle use. Ph.D Thesis, 2013, Université Pierre et Marie Curie.

[14] W. R. Bennett, Considerations for Estimating Electrode Performance in Li-Ion Cells, IEEE Energytech, p1-5, 2012.

[15] N. Jin, D. L. Danilov, P. PM. J Van den Hof, M.C.F. Donkers. Parameter estimation of an electrochemistry-based lithium-ion battery model using a two-step procedure and a parameter sensitivity analysis. International Journal of Energy Research, 2018.

[16] M. Dubarry, V. Svoboda, R. Hwu, and B. Y. Liaw. Incremental Capacity Analysis and Close-to-Equilibrium OCV Measurements to Quantify Capacity Fade in Commercial Rechargeable Lithium Batteries. Electrochem. Solid-State Lett., vol. 9, (10), A454-A457, 2006.

[17] C. Forgez, V. Do Dinh, G. Friedrich, M. Morcrette, C. Delacourt. Thermal modeling of a cylindrical $\mathrm{LiFePO}_{4} /$ graphite 
lithium-ion battery. J. Power Sources, vol. 195, (9), pp 29612968, 2010.

[18] M. Dubarry, C. Truchot, B. Y. Liaw. Synthesize battery degradation modes via a diagnostic and prognostic model. J. Power Source, vol. 219, pp $204-216,2012$.

[19] M. Dubarry, N. Vuillaume, B. Y. Liaw, From single cell model to battery pack simulation for Li-ion batteries, J. Power Sources, vol. 186 (2), pp. 500-507, 2009.

[20] N. Damay. Contribution à la modélisation thermique de packs batteries LiFePO4 pour véhicules décarbonés. Ph.D. Thesis, 2015, Université de technologie de Compiègne.

[21] N. Damay, C. Forgez, M-Pierre Bichat, G. Friedrich. Thermal modeling of large prismatic LiFePO4-graphite battery. Coupled thermal and heat generation models for characterization and simulation. J. Power Sources, vol. 283, pp. 37-45, 2015.

[22] M. Therese von Srbik, M. Marinescu, R. F. Martinez-Botas, G. J. Offer. A physically meaningful equivalent circuit network model of a lithium-ion battery accounting for local electrochemical and thermal behaviour, variable double layer capacitance and degradation. J. Power Sources, vol. 325, pp. 171-184, 2016.

[23] E. Prada, D. Di Domenico, Y. Creff, J. Bernard, V. SauvantMoynot, F. Huet. Simplified Electrochemical and Thermal Model of LiFePO4-Graphite Li-Ion Batteries for Fast Charge Applications. J. Electrochem. Soc., vol. 159, A1508-A1519, 2012.

[24] R. Raccichini, M. Amores, G. Hinds. Critical Review of the Use of Reference Electrodes in Li-Ion Batteries: A Diagnostic Perspective. Batteries, vol. 5, pp. 12, 2019.

[25] W. Dreyer, J. Jamnik, C. Guhlke, R. Huth, J. Moskon, M. Gaberscek. The thermodynamic origin of hysteresis in insertion batteries. Nature, vol. 9, pp. 1-6, 2010.

[26] R. Yazami, Y. Reynier. Thermodynamics and crystal structure anomalies in lithium-intercalated graphite. J. Power Sources, vol. 153, (2), pp 312-318, 2006.

[27] B. Wu, Y. Ren, N. Li. $\mathrm{LiFePO}_{4}$ Cathode Material. In: S. Soylu (ed.), Electric Vehicles : The Benefits and Barriers, InTech Publisher, Shangai, 2011, pp. 199-216. Available from: http://www.intechopen.com/books/electric-vehicles-thebenefits-and-barriers/lifepo4-cathode-material

[28] Y. F. Reynier, R. Yazami, B. Fultz, Thermodynamics of Lithium Intercalation into Graphites and Disordered Carbons. J. Electrochem. Soc., vol. 151, A422-A426, 2004.

[29] C. Liu, Z. G. Neale, G. Cao. Understanding electrochemical potentials of cathode materials in rechargeable batteries. Materials Today, vol. 19, 2016.

[30] N. Marx, L. Croguennec, D. Carlier, L. Bourgeois, P. Kubiak, F.d.r.L. Cras, C. Delmas. Structural and Electrochemical Study of a New Crystalline Hydrated Iron(III) Phosphate $\mathrm{FePO}_{4} \cdot \mathrm{H}_{2} \mathrm{O}$ Obtained from $\mathrm{LiFePO}_{4}(\mathrm{OH})$ by Ion Exchange. Chem. Mater. vol. 22, p1854-1861, 2010.

[31] J.-F. Martin, M. Cuisinier, N. Dupré, A. Yamada, R. Kanno, D. Guyomard. More on the reactivity of olivine LiFePO4 nanoparticles with atmosphere at moderate temperature. J. Power Sources, 196, pp. 2155-2163, 2011.

[32] M. Cuisinier, J.-F. Martin, N. Dupre, R. Kanno, D. Guyomard Elucidating the $\mathrm{LiFePO}_{4}$ air aging mechanism to predict its electrochemical performance. J. Mater. Chem. vol. 21, 18575 18583, 2011.

[33] M. Wilka, A. Hoffmann, R. Stern, M.Wohlfahrt-Mehrens. Influence of anode/cathode balancing on cycling stability of lithium ion cells. Abstract $\sharp 844$, Honolulu PRIME 2012, ECS- Electroch. Soc., 2012.

[34] H. Ekström "Electrode Balancing of a Lithium-Ion Battery with COMSOL", https://www.comsol.com/blogs/electrodebalancing-of-a-lithium-ion-battery-with-comsol/, visited the 11th December 2019.

[35] C.-S. Kim, K. M. Jeong, K. Kim, C.-W Yi. Effects of Capacity Ratios between Anode and Cathode on Electrochemical Properties for Lithium Polymer Batteries. Electrochimica Acta, vol. 155, pp. 431-436, 2015.

[36] K. Kleiner, P. Jakes, S. Scharner, V. Liebau, Helmut Ehrenberg. Changes of the balancing between anode and cathode due to fatigue in commercial lithium-ion cells. J. Power Sources, vol. $317,25-34,2016$

[37] C. R. Birkl, M.R. Roberts, E. McTurk, P.G. Bruce, D. A. Howey. Degradation diagnostics for lithium ion cells. J. Power Sources, vol. 341, pp. 373-386, 2017.

[38] P. Arora, M. Doyle, R. E. White. Mathematical Modeling of the Lithium Deposition Overcharge Reaction in Lithium-Ion Batteries Using Carbon-Based Negative Electrodes. J. Electrochem. Soc., vol. 146,(10), pp. 3543-3553, 1999.

[39] T. Waldmann, B.I. Hogg, M. Wohlfahrt-Mehrens. Li plating as unwanted side reaction in commercial Li-ion cells-A review. J. Power Sources, vol. 384, pp. 107-12, 2018.

[40] B. Writer. Anode Materials, SEI, Carbon, Graphite, Conductivity, Graphene, Reversible, Formation. In: Lithium-Ion Batteries. Springer, Cham, pp 1-71, 2019.

[41] D. Allart, M. Montaru, H. Gualous. Model of Lithium Intercalation into Graphite by Potentiometric Analysis with Equilibrium and Entropy Change Curves of Graphite Electrode. J. Electrochem Soc., vol. 165, A380-A387, 2018.

[42] P. Arora, M. Doyle, R. E. White. Mathematical Modeling of the Lithium Deposition Overcharge Reaction in Lithium-Ion Batteries Using Carbon-Based Negative Electrodes. J. Electrochem Soc., vol. 146, 3543-3553, 1999.

[43] H. Berg. Frontmatter. In Batteries for Electric Vehicles: Materials and Electrochemistry (pp. I-Iv). Cambridge: Cambridge University Press, 2015. 